\title{
Lusioersily
}

\section{Development of an embedded thin-film strain-gauge-based SHM network into 3D- woven composite structure for wind turbine blades}

Zhao, D., Rasool, S., Forde, M., Weafer, B., Archer, E., Mcllhagger, A., \& McLaughlin, J. (2017). Development of an embedded thin-film strain-gauge-based SHM network into 3D-woven composite structure for wind turbine blades. In Unknown Host Publication SPIE. https://doi.org/10.1117/12.2259808

Link to publication record in Ulster University Research Portal

\section{Published in:}

Unknown Host Publication

Publication Status:

Published online: 19/04/2017

DOI:

$10.1117 / 12.2259808$

\section{Document Version}

Author Accepted version

\section{General rights}

Copyright for the publications made accessible via Ulster University's Research Portal is retained by the author(s) and / or other copyright owners and it is a condition of accessing these publications that users recognise and abide by the legal requirements associated with these rights.

\section{Take down policy}

The Research Portal is Ulster University's institutional repository that provides access to Ulster's research outputs. Every effort has been made to ensure that content in the Research Portal does not infringe any person's rights, or applicable UK laws. If you discover content in the Research Portal that you believe breaches copyright or violates any law, please contact pure-support@ulster.ac.uk. 


\section{Development of an embedded thin- film strain-gauge-based SHM network into 3D-woven composite structure for wind turbine blades}

Dongning Zhao, Shafqat Rasool, Micheal Forde, Bryan Weafer, Edward Archer, et al.

Dongning Zhao, Shafqat Rasool, Micheal Forde, Bryan Weafer, Edward Archer, Alistair Mcllhagger, James McLaughlin, "Development of an embedded thin-film strain-gauge-based SHM network into 3D-woven composite structure for wind turbine blades," Proc. SPIE 10171, Smart Materials and Nondestructive Evaluation for Energy Systems 2017, 101710C (19 April 2017); doi: 10.1117/12.2259808 Health Monitoring, 2017, Portland, Oregon, United States 


\title{
Development of an Embedded Thin-film Strain-gauge-based SHM Network into 3D-woven Composite Structure for Wind Turbine Blades
}

\author{
Dongning Zhao*a, Shafqat Rasool ${ }^{\mathrm{a}}$, Micheal Forde ${ }^{\mathrm{b}}$, Bryan Weafer ${ }^{\mathrm{b}}$, Edward Archer ${ }^{\mathrm{a}}$, Alistair \\ McIlhagger ${ }^{\mathrm{a}}$, James McLaughlin ${ }^{\mathrm{a}}$ \\ ${ }^{a}$ School of Engineering, University of Ulster, Newtownabbey, BT370QB, UK; ${ }^{b}$ Éire Composites \\ Teo., Indreabhán, Co. Galway, IRELAND
}

\begin{abstract}
Recently, there has been increasing demand in developing low-cost, effective structure health monitoring system to be embedded into 3D-woven composite wind turbine blades to determine structural integrity and presence of defects. With measuring the strain and temperature inside composites at both in-situ blade resin curing and in-service stages, we are developing a novel scheme to embed a resistive-strain-based thin-metal-film sensory into the blade spar-cap that is made of composite laminates to determine structural integrity and presence of defects. Thus, with fiberglass, epoxy, and a thinmetal-film sensing element, a three-part, low-cost, smart composite laminate is developed. Embedded strain sensory inside composite laminate prototype survived after laminate curing process. The internal strain reading from embedded strain sensor under three-point-bending test standard is comparable. It proves that our proposed method will provide another SHM alternative to reduce sensing costs during the renewable green energy generation.
\end{abstract}

Keywords: Smart material, thin-film sensor, strain gauge, 3D-woven composites, composite structures, structural health monitoring, sensors, SHM, NDE

\section{INTRODUCTION}

In recent years for renewable energy industry, there has been increasing demand in developing low-cost, effective structure health monitoring/sensing system to be embedded into 2D or 3D-woven composite wind turbine blades to determine structural integrity and presence of defects. In addition to this, wind renewable energy is a major growing sector of the energy industry which is getting particular attention in the world due to the vast natural resources available.

Modern megawatt-scale wind turbine blades are typically over 50m long and carbon fibre reinforced polymer(CFRP) have been developed for longer blades to increase strength and reduce weight, but disadvantage is that any internal damage cannot be seen from outside.

Uniquely for wind energy industry, wind turbines are often located in remote areas, such as offshore, requiring time, money, and planning to visit for inspection or maintenance. Majority of the operation and maintenance costs and downtime are caused by corrective maintenance, e.g. blade fracture. If a substantial part of those efforts can be shifted from corrective to structure-health-information based maintenance, this will lead to lower maintenance costs, less down time, and repairs can be combined with already planned preventive maintenance for better planning and use of resources.

Composite carbon fiber blades along accounts for $40 \%$ of cost of the one wind turbine unit, and most wind turbines are designed to last at least 15 years. The largest number of wind turbine accident is accounted for blade failure. So it is important to perform structure health monitoring to detect damage before structure failure of wind turbine blades occurs, both blade and structural failure are costly [1].

3D-woven composites are very attractive material for spar caps of wind turbine rotor blades. Carbon or Carbon/glass fibre hybrid 3D-woven composite have a great deal of potential for reducing processing cost by saving in lay-up time, higher impact performance, improvements in through thickness properties, and higher resistance to delamination [2].

*d.zhao@ulster.ac.uk; phone 442890 368933; fax 4428 366863; nibec.ulster.ac.uk

Smart Materials and Nondestructive Evaluation for Energy Systems 2017,

edited by Norbert G. Meyendorf, Proc. of SPIE Vol. 10171, 101710C

(c) 2017 SPIE · CCC code: $0277-786 X / 17 / \$ 18 \cdot$ doi: $10.1117 / 12.2259808$ 


\subsection{Structural health monitoring (SHM)}

Structural health monitoring (SHM) is a revolutionary method of determining the integrity of structures involving the use of multidisciplinary fields including sensors, materials, signal processing, system integration, and signal interrogation [3, 4]. SHM systems have the potential to continually monitor the health of a structure through strategically located sensors coupled with monitoring technology enabling remote interrogation of the sensors.

In blade structure, moisture absorbing, fatigue, wind gusts, or lightning strikes may cause damage to wind turbine blades. Anomalies like delamination between layers, matrix cracking, fiber breakage, and fiber buckling all produce stress and strain concentrations. Knowing the integrity of in-service structures on a continuous real-time basis is a very important objective for blade manufacturers and maintenance teams to reduce maintenance and re-calibration activities $[1,3$, and 4]. An SHM system for a wind turbine should be able to detect damage at the component level, meaning that damage requiring a repair should be detected well before component/blade failure occurs. It provides more efficient and effective maintenance procedures with substantially reduced downtime and maintenance cost.

\subsection{Recent SHM technology development}

Recent advances in sensor technology, material processing, damage modeling, and system integration have enabled new developments in structural evaluation and inspection technologies to overcome the shortcomings of the existing inspection systems [1,7].

Several types of traditional sensors have been investigated for SHM applications in wind turbine blade, including visual inspection, infrared thermograph, surfaced-mounted strain gauge, accelerometer, ultrasonic sensors, acoustic sensors (acoustic emission), fiber optic sensors, or detect defects by non-destructive test methods such as x-ray scans. Those approaches are often expensive, time-consuming and complicated to be implemented.

Visual inspection cannot detect cracks inside blades, and not suitable for automated applications in real time. AE [5] only detects local damage and thus requires sensors close to the point of damage, which may not be feasible on a large structure if the location of damage is not known beforehand. Infrared thermography techniques work well in laboratory settings [6], but most require the target material to be actively heated, so online monitoring of large structures using infrared is not yet practical and not suitable in situ fatigue monitoring. Many other NDE techniques suffer from similar setbacks. The wind energy industry already uses ultrasonic testing techniques for blade evaluation, but not in an online SHM scenario.

Most recently, most effort has been concentrated on the embedment of fibre optical sensors within glass and carbon reinforced polymers [7, 8, and 9], e.g. fibre Bragg grating (FBG), one cable can contain multiple sensors, reducing the number of wires. Fibre optical sensor based approach is not only expensive, but also can only measure local properties where the sensor is located. Moreover, it's difficult to align when it's deployed inside composites during embedment.

But cost presents a particularly large barrier for mass deployment of blade SHM systems, because the technologies best suited for monitoring blades, e.g. fibre optic sensor system, tend to be expensive. In this paper, we are proposing a novel scheme to embed a resistive-strain-based thin-metal-film sensory into the blade spar-cap that is made of composite laminates to determine structural integrity and presence of defects.

\section{PROPOSED THIN-FILM-STRAIN-SENSOR EMBEDMENT FOR SHM}

Blade SHM is challenging because the aerodynamics of the blades are critical for efficient power production, so an SHM system must not interfere with aerodynamics or structure integrity. We proposed to embed a resistive-strain-based thinmetal-film sensory into the blade spar-cap that is made of composite laminates to determine structural integrity and presence of defects. With measuring the internal strain and/or temperature inside composites at both in-situ blade resin curing and in-service stages, the damage status inside the blade can be evaluated through the analysis of those sensor signals. As it is impractical to put sensor everywhere, SHM will be mainly used for hot spot or critical area monitoring.

To monitor in situ the structure health condition of in-service wind turbine blades, the essential two major components of a SHM system include the Integrated hardware sensor network as the front-end part and sensing data acquisition and interrogation system as the back-end part. We intend to provide SHM service for all stages of the blade from manufacturing to in-service SHM monitoring. Those 3 stage of SHM monitoring are shown in the following: 
1. Internal strain measurement during resin manufacturing (curing) stage;

2. Transportation stage (Damage prevention/ monitoring);

3. In-service SHM - monitoring the component during daily operation.

In this section, we concentrate on the task to provide SHM service for in-service SHM - monitoring the blade during daily operation.

\subsection{Sensor enabling technology and integration}

As wind turbine blade has a highly attenuative composite structure, e.g. thick, wove, and multi-layered structures, for sensing signals to be transmitted inside blade. With the advancement of sensor manufacturing technology, especially MEMS technology, miniaturization of thin metal files with strain-sensor (micro-sensor) arrays suitable for embedment in composite for SHM purpose is possible.

Using embedded resistive-based strain sensory to determine the structural integrity is an effective and low-cost way of determining the health of the composite structure. This method provides sensor protection while in embedment, and it's robust and simple to implement.

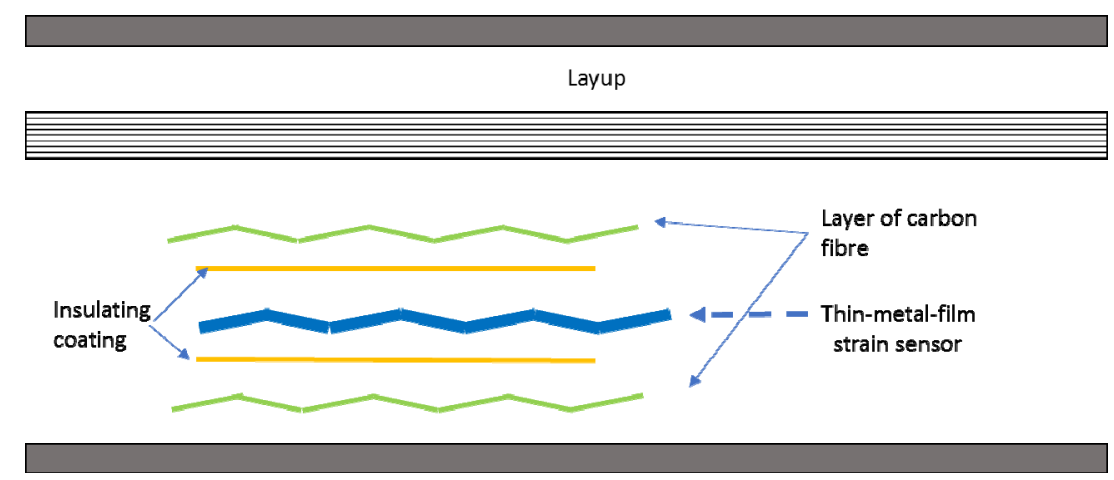

Figure 1. Diagram of thin-metal-film strain senor embedded into composite.

The thin-metal-film strain sensor is embedded and the electric circuitry (including signal process unit) will be surfaceattached onto the composite laminate. It is comprised of wired connectivity at the local hot spots with wireless transmission capability.

\subsection{Resistive / Electric strain gauge}

The resistive (or electric) strain gage consists of a very fine wire or metallic foil arranged in a grid pattern, subjecting to strain in the parallel direction. The cross-sectional area of the grid is minimized to reduce the effect of shear strain and Poisson Strain. The grid is bonded to a thin backing, called the carrier, which is attached directly to the test specimen.

The material of the embedded component must be carefully selected to be compatible with the host material. Regarding to the metal alloy for sensing element (thin-film), the metal alloy must be very thin for embedment, comparative smaller size W.R.T resin fibre. Also, this metal alloy must be sensitive to measurement. Most popular metal alloys are $\mathrm{NiCr}$ (Nichrome) and Constantan (55\% copper\& 45\% nickel). Both show low resistance, minor temperature dependence, and high elongation characteristics. Other alternatives under other research investigations are Celion, Panex, and Texalium. The particular resistive strain sensing element used in the study is sourced from Kyowa, which has $5 \mathrm{~mm}$ gauge length with temperature rated up to $185^{\circ} \mathrm{C}$. This sensor has a resolution of $1 \mathrm{uE}$ and is developed specially for epoxy matrix resin composites.

The gauge used has a polyimide substrate, and both sides are pre-treated with epoxy power to provide insulation to prevent short circuit with conductive carbon fibres, as Teflon material will cause defective on our resin and not suited for our experiment. The fly wires come pre-attached to the gauge for soldering to terminal pads, are also be insulated by high-temperature polyimide tape to prevent short circuit with conductive carbon fibres. 


\subsection{Sensor signal condition system}

Wheatstone quarter-bridge circuit from LARD v-link system by Microstrain System is used to extract sensing signal and signal process. As output signal is weak, and it may need amplification in noisy environment.

\subsection{Experiments and measurements}

One thin-metal-film strain gauge was embedded into our laminate. Prototypes of such 2D and 3D-woven sensing composite laminates are constructed from layers of Toray fiberglass and resin prepreg using the recommended cure cycle. Integrating the thin-metal-film sensor within the composite laminate provides a sensing element that measures structural behaviour. Thus, with fiberglass, epoxy, and a thin-metal-film sensing element, a three-part, low-cost, smart composite laminate is developed. Vacuum consolidation method was used to manufacture UD and 3D-woven composite.

\subsubsection{Manufacturing process}

For UD laminate manufacturing with 6-carbon layers, epoxy powder was weighed to have approximately 50\% FVF in the final composite. Epoxy powder was spread onto the fabric plies layer by layer. For 3D-woven carbon fibre composites, it was not possible to apply epoxy powder layer by layer in 3D woven reinforcement. The powder was spread at the bottom and at the top of the 3D reinforcement. After laying up the fabric and epoxy powder, the lay-up was bagged using nylon film and tack tape and vacuum was applied using a vacuum pump. The set-up was held at a temperature of $50^{\circ} \mathrm{C}$ in an oven for overnight for drying of epoxy powder. After that temperature was raised to $180^{\circ} \mathrm{C}$ and the process was held at $180^{\circ} \mathrm{C}$ for 2.5 hours. After 2.5 hours, the mould was cooled down to room temperature to get the consolidated composite laminates.

\subsubsection{Microsection analysis of cross-section of prototype laminate}

A prototype laminate was manufactured to assess the adhesion of the gauges to the powder epoxy. Three gauges were embedded 1 ply deep in a 4 ply 2D laminate. The sample was cured in the oven and it is C-Scanned and cut up for microsection analysis. The following figure shows the ultrasonic C-scan of the laminate panel with three strain gauges embedded. The colours suggest there is no indication of delamination or void formation in the laminate. This is a good indication of the sensory is well bonded inside the laminate. It means there is no indication of delamination or void formation inside the laminate.

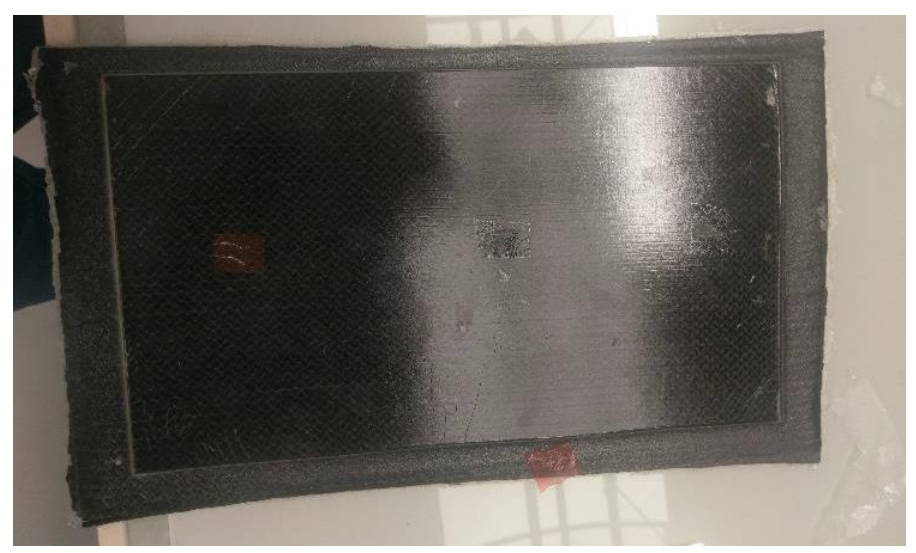

Figure 2. Laminate sample of three gauges embedded 1 ply deep in a 4 ply 2D laminate.

The following figure shows the ultrasonic C-scan of the laminate panel with three strain gauges embedded. The colors suggest there is no indication of delamination or void formation in the laminate. This is a good indication of the sensory is well bonded inside the laminate. 


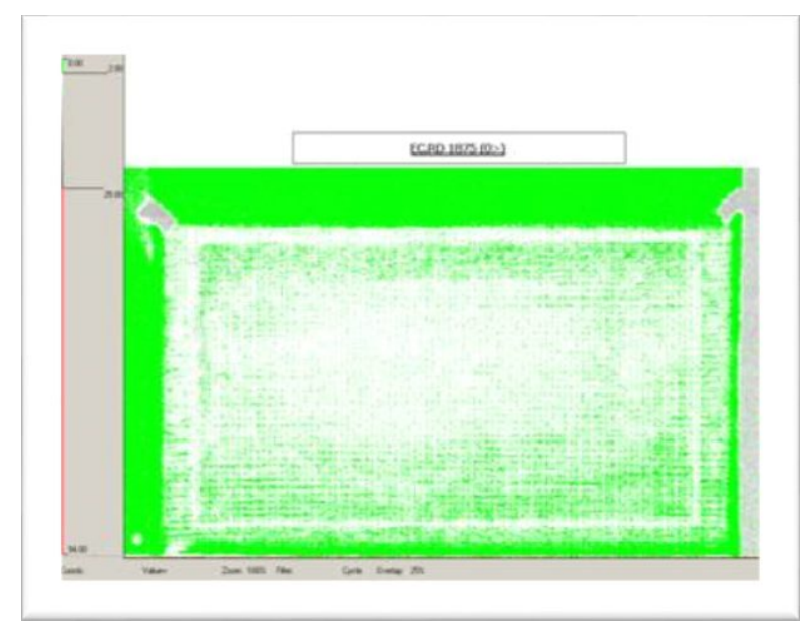

Figure 3. C-scan picture of 3 strain gauge embedded in composite laminate.

After C-scan picture taken, this laminate is cut up and the cross section of the embedded gauges with resin surrounding is inspected to verify the mechanical coupling at resin matrix around sensor, and determine any detrimental effect caused by such embedment. In Figure 4, top left corner, the white dotted line is thin-metal-film from one embedded strain gauge.

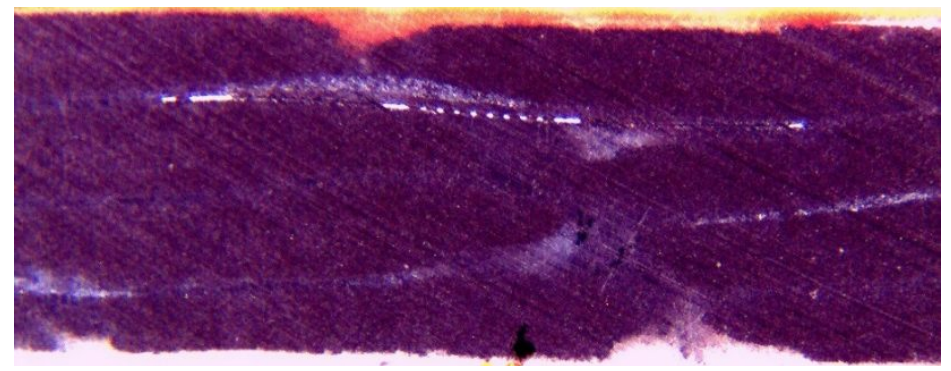

Figure 4. Cross-section view of strain gauge embedded in 2D 4layer laminate under microscope.

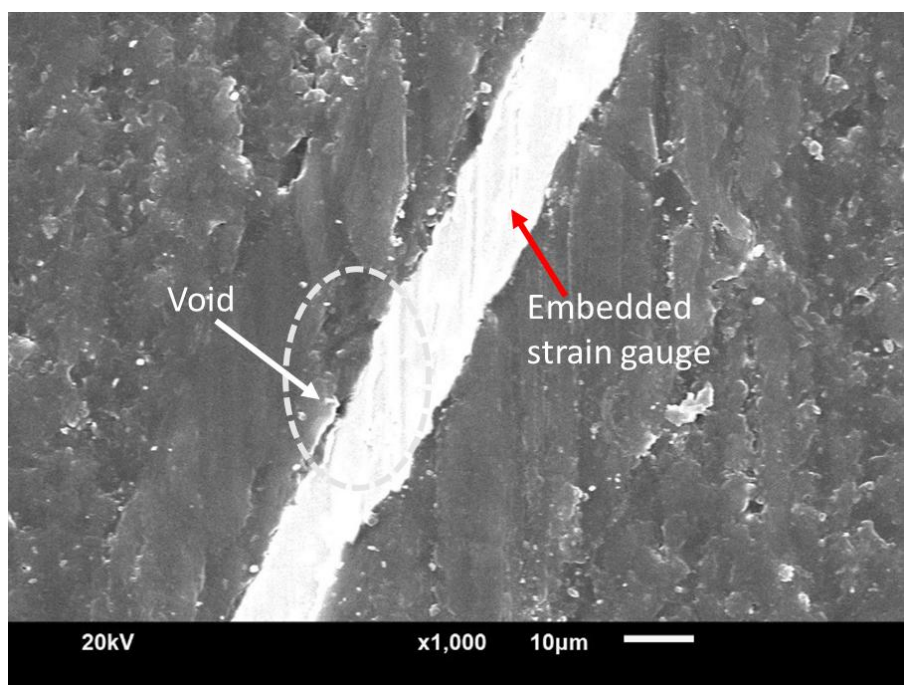

Figure 5. Cross-section SEM view of strain gauge embedded in 2D 4layer laminate. 


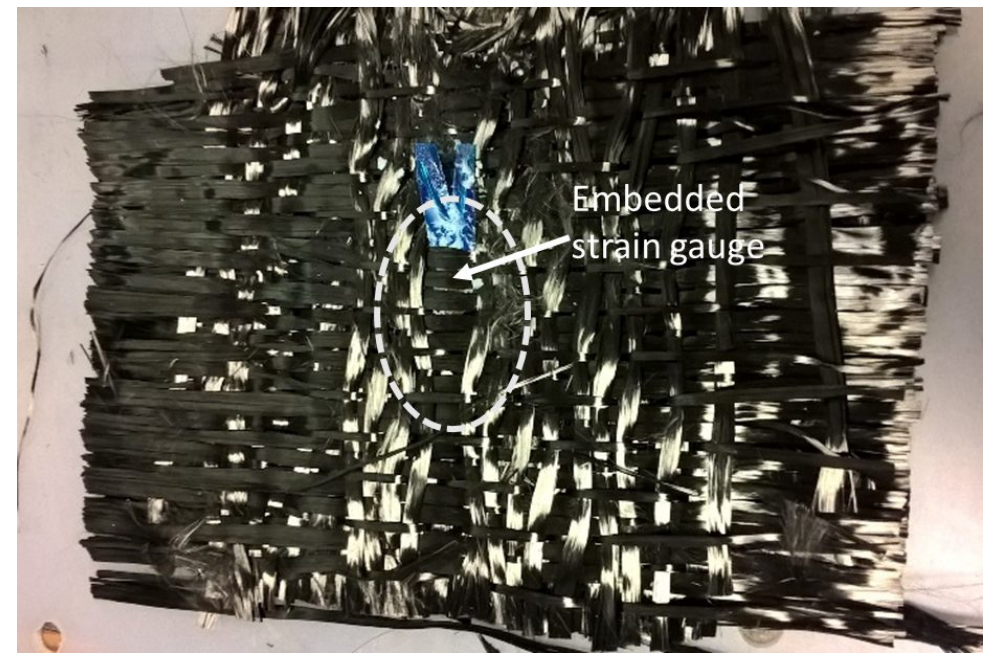

Figure 6. 3D-woven 6-layer carbon fibre with stain gauge embedded, before curing.

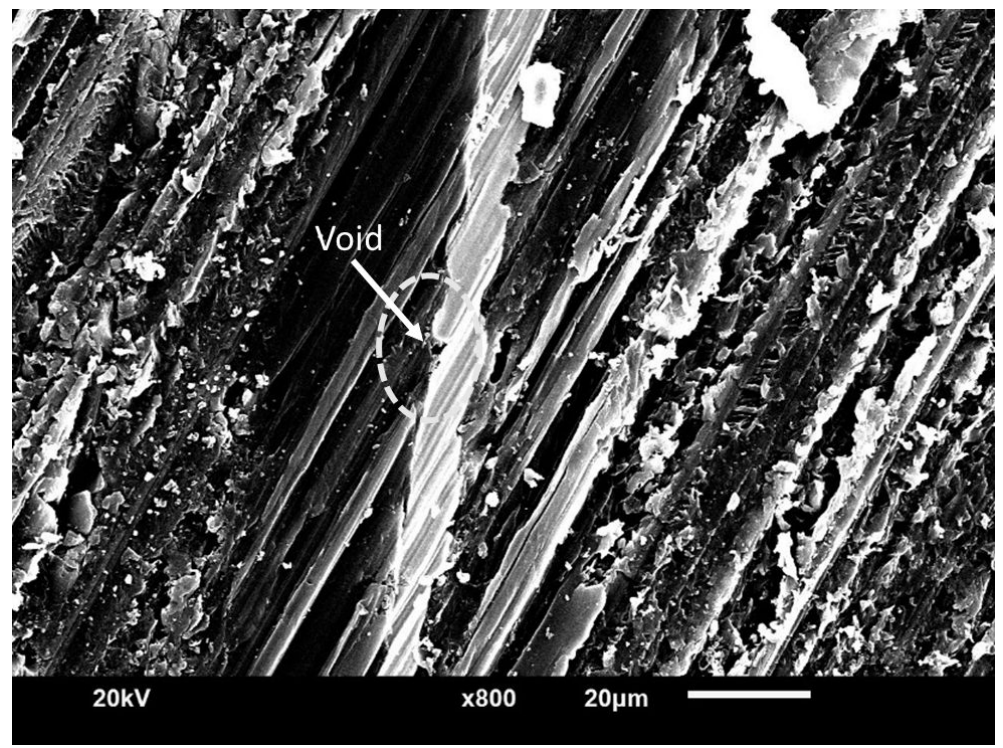

Figure 7. SEM picture of 3D-woven 6-layer carbon fibre with stain gauge embedded. Void area is encircled.

In both $2 \mathrm{D}$ and 3D-woven compsoite laminate samples, SEM pictures show that voids between strain gauge and the resin matrix around the sensor after the manufacturing stage are small and negligible, which have less effects to have any contribution to possible delamination inside laminate.

\subsubsection{Internal /Embedded strain measurement and discussion}

Microstrain value of internal strain inside the composite laminate was measured during initial bending test. Initial strain measurements on the prototype were conducted with Microstrain LORD v-link equipment.

The composite laminate with the integrated SHM system were to be tested under flexural loading test standards of ASTM D790, which is Standard Test Method for Flexural Properties of Polymer Matrix Composite Materials. To verify 
the mechanical coupling at resin matrix around sensor, and determine any detrimental effect caused by embedment, a three-point bending / flexural test was used initially. As delamination would have no effect on the sample strength during a tension test because there are no inter-laminar forces being exhibited, tensile test is not conducted in our experiment.

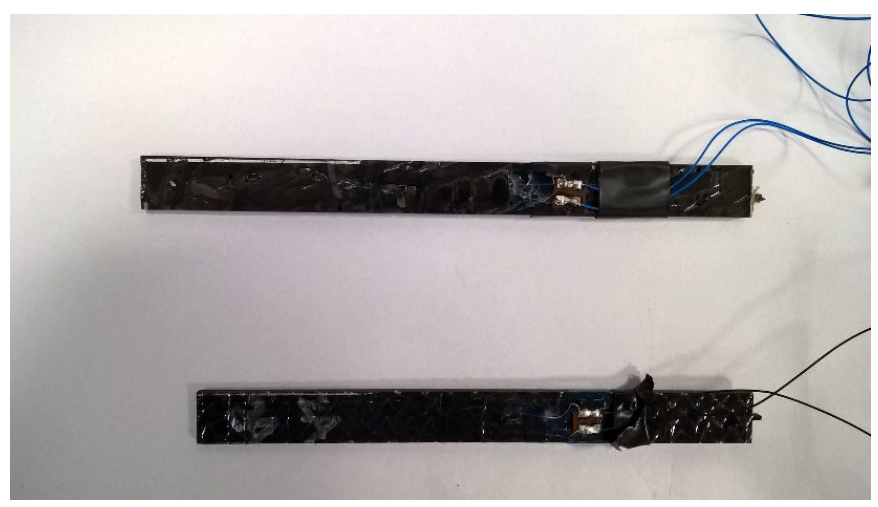

Figure 8. Pictures of 2D (bottom) and 3D-woven (top) test coupon.

A comparison of the stress-strain curves of 2D material with calculated strain using ASTM 790 as well as strain measured through strain gauge embedded inside the $2 \mathrm{D}$ material is shown in figure 9. A similar comparison of 3Dwoven composite is given in figure 10. In both cases, strain gauge survived the manufacturing process and provided corresponding internal strain data.

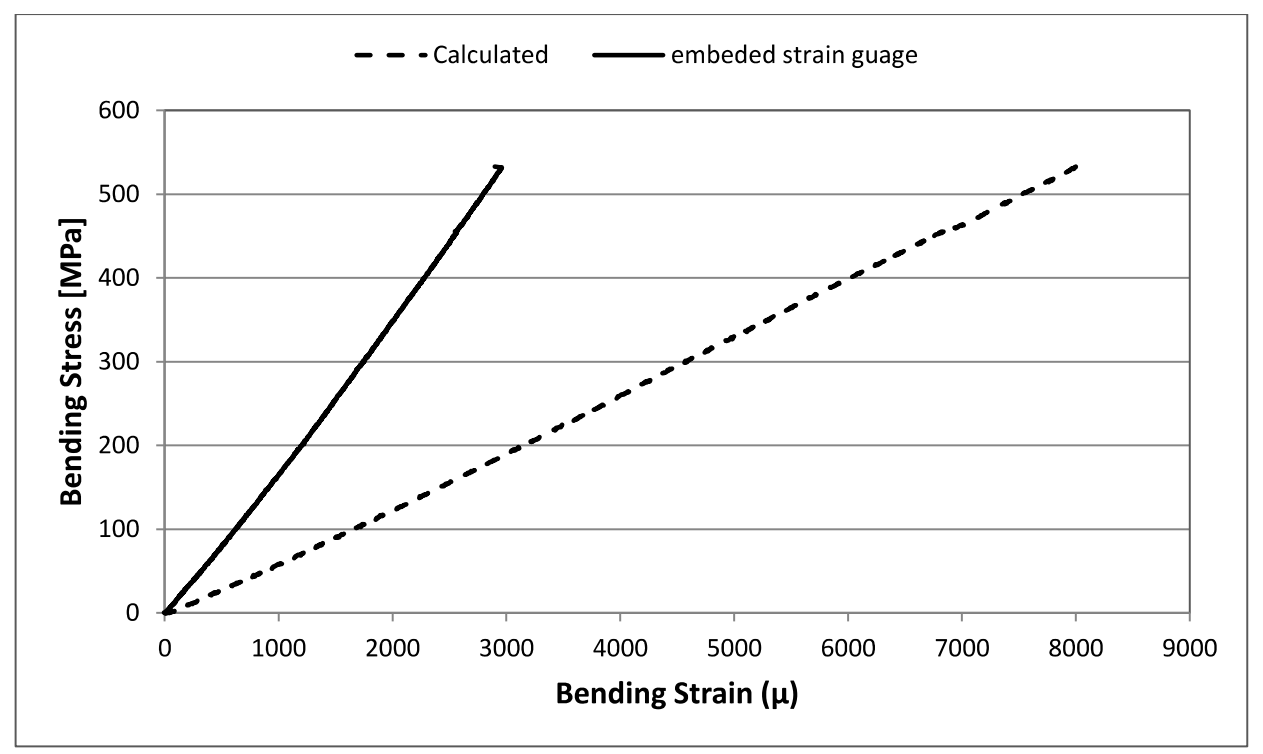

Figure 9. Comparison plots of measured internal/embedded strain value against theoretical value inside 2D laminate.

For both 2D and 3D materials, the calculated strain is higher than the strain measured with embedded strain gauges. The possible reason for this behaviour is that the calculated strain is obtained from the displacement in the outer fibre as a result of application of force. The distance of embedded strain from neutral axis is less as compared to the surface of the laminate. The strain is directly related to the distance from the neutral axis. A similar behaviour has been observed by Archer et al [10] in tensile strain behaviour of 3D woven composite with embedded fibre optic sensor. They have 
observed a difference in strain measured through fibre optic sensor embedded under first and second plies and strain measured through surface mounted strain gauges. The difference became larger for specimens where the fibre optic sensor was embedded further in the inner third and fourth plies.

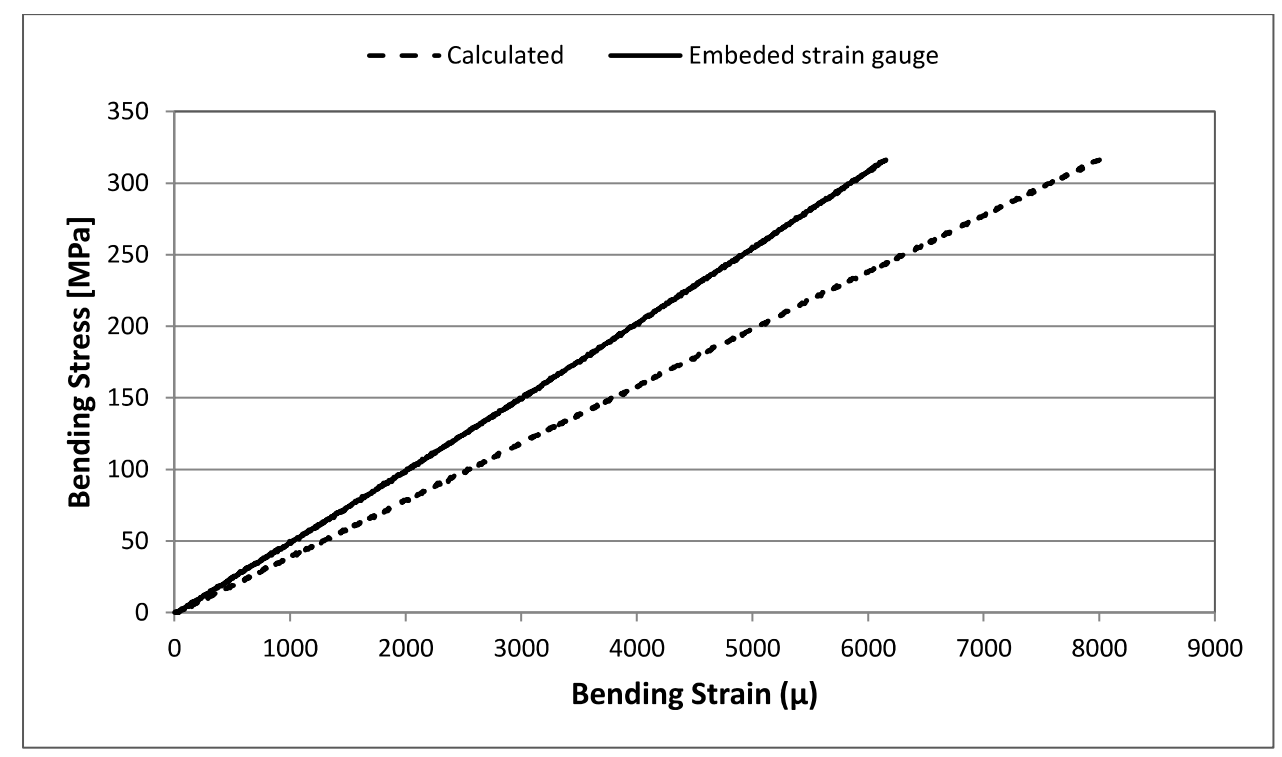

Figure 10. Comparison plots of measured internal/embedded strain value against theoretical value inside 3D-woven laminate.

\section{CONCLUSIONS}

Concept of embedding thin-metal-film strain gauge sensor into 2D and 3D-woven resin was introduced. C-scan picture shows the strain sensor is well bonded inside the composite laminate. In both 2D and 3D-woven sample SEM pictures, the voids between thin-film and composite resin is negligible. The bending tests show the feasibility of embedding thinmetal-film strain-measuring sensor into composites to monitoring composite spar cap structure at in-service stages. As on-going research project in the future, more laminate samples with different 3D-woven carbon fibre structure and fatigue testing will be conducted. Our proposed method will provide another SHM alternative to reduce sensing costs during the renewable green energy generation.

\section{REFERENCES}

[1] Ciang, C.C. Lee, J. R. and Bang, H. J., "Structural health monitoring for a wind turbine system: a review of damage detection methods," Measurement science and technology, 19 (2008) 122001.

[2] Broderick, J. Mcllhagge, A.T., Advancement of 3D woven composites through embedded in situ strain measurement, PhD thesis, University of Ulster, May 2011.

[3] Ikegami, R., "Structural Health Monitoring: Assessment of Aircraft Customer Needs," Proceedings of the 2nd International Workshop on Structural Health Monitoring, Stanford, CA, September 8-10. 1999.

[4] Chang, F., "Ultra Reliable and Super Safe Structure for the New Century," Proc. of the 1st European Workshop on Structural Health Monitoring, Balageas, pp. 3-12. 2002.

[5] Frankenstein, B. Schubert, L. Meyendorf, N. Freidmann, H. and Ebert. C, "Monitoring system of wind turbine rotor blades," Proc. SPIE 7293 (2009). Doi:10.1117/12.815464 
[6] Zhao, S. Zhang, C, Wu, N. Duan, Y. and Li, H., "Infrared thermal wave nondestructive testing for rotor blades in wind turbine generators non-destructive evaluation and damage monitoring," Proc. SPIE 7383, Beijing, 2009

[7] Schubel. P.J. Crossley, R.J. Boateng, E.K.G. Hutchinson, J.R., "Review of structural health and cure monitoring techniques for large wind turbine Blades," Renewable Energy, 12 October 2012.

[8] Raffaella Di Sante, "Fibre Optic Sensors for Structural Health Monitoring of Aircraft Composite Structures: Recent Advances and Applications," Journal of Sensors, 30 July 2015.

[9] Chen, Y. Ni, YQ. Ye, X.W. and Zhu, S.," Structural health monitoring of wind turbine blade using fiber Bragg grating sensors and fiber optic rotary joint," Proc. SPIE 8345 (2012), pp. 834534

[10] Archer, A. Broderick, J. Buchanan, J and McIlhagger A.T; Internal strain measurement and impact response of three-dimensional angle interlock woven carbon fiber composites, Journal of Reinforced Plastics and Composites, 0(00) 1-13, 2013. 